•研究报告・

\title{
海南苏铁种群结构与森林群落郁闭度的关系
}

\author{
吴二焕 ${ }^{1}$, 李东海 ${ }^{2 *}$, 杨小波 ${ }^{2}$, 左永令 ${ }^{2}$, 李龙 ${ }^{2}$, 张培春 ${ }^{2}$, 陈琳 $^{2}$, 田路嘉 ${ }^{2}$, 李晨笛 ${ }^{2}$
}

1. 海南大学生命科学与药学院, 海口 570228; 2. 海南大学生态与环境学院, 海口 570228

摘要: 海南苏铁(Cycas hainanensis)是古老的苏铁属植物, 为国家 I 级重点保护植物, 也是IUCN红色名录的濒危物种。为研究 海南苏铁在海南昌江保梅岭省级自然保护区的种群结构与森林郁闭度的关系, 本文通过样方法对海南苏铁种群及其所在群 落进行调查, 分析了其群落结构和物种多样性, 以及其种群密度、年龄结构、存活曲线、空间分布格局与森林郁闭度的关系。 结果表明: 海南苏铁所在群落垂直结构分为乔木上下 2 层、灌木层和草本层。海南苏铁所在群落物种多样性指数偏高, 群落内 物种组成丰富; 各样方内海南苏铁数量分布不均, 经常群生于海拔500 $\mathrm{m}$ 左右的林下、林缘间。海南苏铁种群结构属于增长 型, 种群更新力强, 种群存活曲线趋近于Deevey-II型, 死亡率随着龄级增加而增加, 说明海南苏铁种群处于相对稳定的状态, 随着种群个体的生长发育, 其生存力逐渐下降; 海南苏铁种群空间分布格局呈聚集型, 聚集程度指标随着林分郁闭度变大而 增加。曲线估计结果显示, 海南苏铁幼苗幼树在透光率 $36.11 \%-58.33 \%$ 显著增加。综上所述, 昌江保梅岭地区的海南苏铁种 群处于较为稳定的增长状态, 喜生长于海拔5 00 m左右、郁闭度为35\%-60\%的森林环境中。

关键词: 海南苏铁; 群落结构; 种群结构; 存活曲线; 分布格局

吴二焕, 李东海, 杨小波, 左永令, 李龙, 张培春, 陈琳, 田路嘉, 李晨笛 (2021) 海南苏铁种群结构与森林群落郁闭度的关系. 生物多样性, 29, 1461-1469. doi: 10.17520/biods.2021150.

Wu EH, Li DH, Yang XB, Zuo YL, Li L, Zhang PC, Chen L, Tian LJ, Li CD (2021) Populatiom structure of Cycas hainanensis and its relationship with forest canopy density. Biodiversity Science, 29, 1461-1469. doi: 10.17520/biods.2021150.

\section{Population structure of Cycas hainanensis and its relationship with forest canopy density}

Erhuan $\mathrm{Wu}^{1}$, Donghai $\mathrm{Li}^{2 *}$, Xiaobo Yang ${ }^{2 *}$, Yongling Zuo ${ }^{2}$, Long $\mathrm{Li}^{2}$, Peichun Zhang ${ }^{2}$, Lin Chen², Lujia Tian², Chendi $\mathrm{Li}^{2}$

1 School of Life and Pharmaceutical Sciences, Hainan University, Haikou 570228

2 School of Ecology and Environment, Hainan University, Haikou 570228

\begin{abstract}
Aim: Cycas hainanensis, an ancient species of Cycas, is a top priority plant species in China and is also classified as endangered by the International Union for Conservation of Nature (IUCN) Red List. We aim to study the relationship between population structure and forest canopy density of $C$. hainanensis in the Baomeiling Provincial Nature Reserve of Changjiang County, Hainan Province.

Methods: After an investigation of the C. hainanensis population and its community by utilizing the sample survey, we analyzed community characteristics including structure and species diversity, and population characteristics such as age structure, survival curve, spatial patterns, and population density. We also studied the relationship between $C$. hainanensis and forest canopy density.

Results: The vertical structure of the community of $C$. hainanensis was divided into two tree layers, shrub layer and herb layer. The species diversity index of the community was high and the community species composition was rich. The distribution of $C$. hainanensis was uneven in all quadrats and formed clusters in the undergrowth as well as the forest edge at an elevation of $500 \mathrm{~m}$. The population dynamics belonged to growth type, and the population renewal ability is strong. The population survival curve of $C$. hainanensis tended to the Deevey-II type. The population mortality increased with age, which indicated that the population of $C$. hainanensis was in a state of stable growth. The
\end{abstract}


population viability decreased with the growth and development of individual specimens. The spatial distribution pattern of $C$. hainanensis population conformed to clumped distribution, and the degree of aggregation was positively correlated with an increase of forest canopy density. A curve estimation demonstrates that the density of $C$. hainanensis seedlings and saplings increased significantly in the study area where forest canopy density was $36.11 \%-58.33 \%$.

Conclusions: In conclusion, the C. hainanensis population in the Baomeiling Provincal Nature Preserve of Changjiang County is in a stable growth state and preferred to grow in a forest environment with an elevation of approximately 500 $\mathrm{m}$ and forest canopy density of 35\%-60\%.

Key words: Cycas hainanensis; community structure; population structure; survival curve; distribution pattern

种群分布格局是指种群个体在水平空间的配 置状况或分布状态，反映了种群个体在水平空间上 的相互关系, 是植物种群生物学特征对环境生长适 应和选择的结果(郑元润, 1997; 谢宗强等, 1999)。 研究种群的结构和空间分布格局不仅对了解种群 现状及预测种群动态具有重要意义(Bell et al, 2014; Normand et al, 2014), 还可以揭示植物种群与环境 间的关系, 为植物保护提供一定的理论依据(周纪 伦等, 1992)。开展濒危植物群落结构及物种多样性 的研究, 了解其种群的数量动态及演变趋势, 有助 于揭示珍稀植物的濒危过程及濒危机理(张婕等, 2014), 为濒危植物的保护提供理论基础。

森林郁闭度是林地的重要环境因子, 影响林地 内的光照条件, 对林地内植物的生长发育、种群特 征(黄慧敏等, 2018)和多样性(Mestre et al, 2017)等 具有重要影响。根据相关资料, 海南苏铁(Cycas hainanensis)在海南昌江保梅岭有分布且发育较好, 但其在该区域的生长发育与环境的关系如何? 适 宜什么样的生长环境? 目前还没有相关的研究报 道。而且随着保护区的建立, 自然森林植被的恢复 和覆盖度的增加, 保梅岭分布的海南苏铁出现了衰 退现象, 开展森林郁闭度与种群结构的关系研究对 了解海南苏铁种群的生长发育具有重要意义。

海南苏铁是常绿棕㭣状木本植物, 为国家I级 重点保护植物, 被世界自然保护联盟(IUCN)红色名 录列为濒危( $\mathrm{EN}$ )物种, 也是濒危野生动植物种国际 贸易公约(CITES)附录III物种(骆文华等, 2014)。海南 苏铁为我国海南岛特有种, 历史记录表明其主要分 布在霸王岭、吊罗山、尖峰岭、鹦哥岭等地, 生于 海拔 $1,000 \mathrm{~m}$ 以下的热带雨林、山地雨林、季雨林或 次生林和灌从中(陈家瑞, 2004; 杨小波, 2015), 其 研究主要集中在形态结构解剖、系统分类、资源调 查及其保护方面(王定跃和王发样, 1996; 唐源江和
廖景平, 2001; Hill, 2008; 孙湘来等, 2017)。但对海 南苏铁种群动态变化的研究较少, 仅谢春平等 (2019)对五指山地区 3 个样地海南苏铁的种群动态 进行了研究。其结果表明 3 个样地种群均处于稳定 状态, 但不同样地的种群年龄结构存在差异, 其中 1 个样地种群结构为金字塔型, 2 个样地的种群结构 接近于纺锤形, 其存活曲线趋近于Deevey-II型。目 前对海南苏铁种群发育及空间分布格局与其所在 的森林群落郁闭度的关系尚未有报道。因此, 为探 明在森林恢复郁闭度和植物多样性提高之后, 海南 苏铁种群的生存状况与其所在森林群落的变化的 关系, 本文将从群落动态、海南苏铁种群年龄结构 变化和空间分布格局及它们之间的关系等方面开 展研究, 进而探索海南苏铁的濒危机制, 为海南苏 铁的野外回归与保护和种群延续提供基础资料。

\section{材料与方法}

\section{1 研究区概况}

海南省保梅岭省级自然保护区位于海南省西 部丘陵山区 $\left(19^{\circ} 15^{\prime}-19^{\circ} 20^{\prime} \mathrm{N}, 109^{\circ} 03^{\prime}-109^{\circ} 08^{\prime} \mathrm{E}\right)$, 属自然生态系统类森林生态系统类型, 是海南省 西部重要的水源涵养区。保护区总面积 $38.443 \mathrm{~km}^{2}$, 最高海拔847.6 m。该区域为热带海洋季风气候, 有着明显的干湿季, 5-10月为雨季, 旱季为11月至 次年 4 月。年平均气温 $24.9^{\circ} \mathrm{C}$, 年平均降水量 $1,777.4 \mathrm{~mm}$, 年平均蒸发量 $2,070 \mathrm{~mm}$, 年平均相对 湿度77\%, 台风、暴雨、干旱等是保护区主要的自 然灾害。土壤类型主要为砖红壤和赤红壤。砖红壤 主要分布在保护区海拔 $500 \mathrm{~m}$ 以下的山地, 赤红壤 主要分布在海拔500-800 m的低山带。

在该保护区热带天然林内设置6个20 m × $50 \mathrm{~m}$ 的样方(编号依次为 A、B、C、D、E、F), 各样方具 体情况如表1所示。样方总面积 $6,000 \mathrm{~m}^{2}$, 属低山- 
表1 昌江保梅岭自然保护区海南苏铁调查样方的基本情况 Table 1 Physical characteristic of survey quadrat of Cycas hainanensis in the Baomeiling Nature Reserve of Changjiang County

\begin{tabular}{llllll}
\hline $\begin{array}{l}\text { 样方 } \\
\text { Quadrat }\end{array}$ & $\begin{array}{l}\text { 经度 } \\
\text { Longitude Latitude }\end{array}$ & $\begin{array}{l}\text { 纬度 } \\
\text { Altitude (m) }\end{array}$ & $\begin{array}{l}\text { 海拔 } \\
\text { Slope }\end{array}$ & $\begin{array}{l}\text { 坡度 } \\
\text { Slor }\end{array}$ & $\begin{array}{l}\text { 森林郁闭度 } \\
\text { Forest canopy } \\
\text { density }\end{array}$ \\
\hline A & $109^{\circ} 6^{\prime} \mathrm{E}$ & $19^{\circ} 16^{\prime} \mathrm{N}$ & 517.3 & $10.0^{\circ}$ & 0.64 \\
$\mathrm{~B}$ & $109^{\circ} 6^{\prime} \mathrm{E}$ & $19^{\circ} 16^{\prime} \mathrm{N}$ & 519.1 & $12.2^{\circ}$ & 0.51 \\
$\mathrm{C}$ & $109^{\circ} 5^{\prime} \mathrm{E}$ & $19^{\circ} 16^{\prime} \mathrm{N}$ & 512.3 & $14.4^{\circ}$ & 0.47 \\
$\mathrm{D}$ & $109^{\circ} 6^{\prime} \mathrm{E}$ & $19^{\circ} 16^{\prime} \mathrm{N}$ & 510.2 & $14.4^{\circ}$ & 0.29 \\
$\mathrm{E}$ & $109^{\circ} 5^{\prime} \mathrm{E}$ & $19^{\circ} 16^{\prime} \mathrm{N}$ & 504.8 & $10.0^{\circ}$ & 0.59 \\
$\mathrm{~F}$ & $109^{\circ} 6^{\prime} \mathrm{E}$ & $19^{\circ} 16^{\prime} \mathrm{N}$ & 503.6 & $13.8^{\circ}$ & 0.59 \\
\hline
\end{tabular}

高丘陵地貌, 受人类活动的轻微干扰。

\section{2 野外调查与样地设置}

利用相邻样方格子法将整个样地划分成 6 个样 方, 再将每个样方划分成 10 个 $10 \mathrm{~m} \times 10 \mathrm{~m}$ 的小样方, 共60个小样方。对小样方内的物种进行每木调查, 记录小样方内所有高度 $\geq 1.50 \mathrm{~m}$ 植株的种名、胸径、 树高、东西 $\times$ 南北方向的冠幅等。同时对海南苏 铁苗木进行调查, 记录每个小样方内所有海南苏铁 的坐标、叶片数、叶长及坡度等指标; 在每个 $10 \mathrm{~m} \times$ $10 \mathrm{~m}$ 的样方内设置 1 个 $1 \mathrm{~m} \times 1 \mathrm{~m}$ 的草本样方, 调查 草本植物种类、数量; 记录整个样方的生境条件、 植被情况。

\section{3 数据统计与分析}

\subsection{1 海南苏铁所在群落特征}

利用Simpson多样性指数 $(D)$ 、Shannon-Wiener 多样性指数 $\left(H^{\prime}\right)$ 以及Pielou均匀度指数 $(E)$ 分析海南 苏铁所在群落的物种多样性。计算公式如下:

$$
\begin{aligned}
& D=1-\sum_{i=1}^{s} p_{i}^{2} \\
& H^{\prime}=-\sum_{i=1}^{s} p_{i} \ln p_{i} \\
& E=\frac{H^{\prime}}{\ln S} \\
& G=S / \ln A
\end{aligned}
$$

其中, $S$ 为样方内所有物种数目, $p_{i}$ 为群落内第 $\mathrm{i}$ 种的 相对多度, $A$ 为样方面积。

\subsection{2 海南苏铁种群结构}

苏铁类植物生长周期长, 主干生长不明显, 其 年龄大小难以判断，谢春平等(2019)及李娟等(2016) 采用高度级或叶片长度等结构特征替代种群年龄
结构, 分析了种群各龄级的生存和生长动态。结合 本研究实际情况, 参考谢春平等(2019)和李娟等 (2016)的方法, 根据其最长叶片长度进行龄级划分: I级幼苗, 0-50 cm; II级幼树, 50.1-100 cm; III级小树, 100.1-150 cm; IV级中树; 150.1-200 cm; V级大树, 200.1-250 cm; VI级老树, > $250 \mathrm{~cm}$ 。

存活曲线是种群个体在特定年龄段的存活状 态的体现, 其走势反映了种群的生存率随年龄的变 化趋势, 是反映种群动态的重要特征, 由其特定龄 级的相对个体数量绘制得到(李苑菱等, 2017)。

\subsection{3 种群空间分布格局}

根据样方法获得的数据, 采用方差均值比率法 测定整个群落海南苏铁种群的分布格局类型并通 过 $t$ 检验判定显著性, 用 7 种指数测定分析种群分布 格局的聚集强度, 即丛生指数 $(I)$ 、负二项参数 $(k)$ 、 格林指数 $(G I)$ 、Cassie指标 $(C A)$ 、扩散型指数 $\left(I^{\delta}\right)$ 、 平均拥挤度 $\left(\mathrm{m}^{*}\right)$ 、聚集指数(Pai) (茹文明等, 2007 ; 赵瑞白等, 2018)。

\subsection{4 森林郁闭度与透光率}

森林郁闭度是林地中乔木树冠遮蔽地面的程 度, 为树冠投影面积与林地面积之比。通过野外调 查记录的数据计算每个样方的乔木的东西南北 4 个 方向的冠幅, 得到每个样方的总冠幅(李永宁等, 2008):

$$
\text { 冠幅 }=(\text { 东西 } \times \text { 南北 }) / 2
$$

森林郁闭度 $=$ 每个样方乔木总冠幅 $/$ 每个样方 的样方面积

于2020年7月19日至2021年3月11日在编号C (2 个)、 $\mathrm{D}(1$ 个)、 $\mathrm{E}(1$ 个)、 $\mathrm{F}(1$ 个 $)$ 的样方中设置 5 个不 同光照条件的小样方, 每个小样方悬挂一个 UA-002-64温度照度记录仪进行监测, 以记录样方 内的光照强度, 并以空旷无植物遮蔽地方的光强为 对照。用透光率表示相对光照强度的大小, 透光率 $=$ 实测光照强度/对照光照强度 $\times 100 \%$ (秦坤蓉, $2017^{(1)}$; 曹悦等, 2019)。

参照《森林生态学》(薛建辉, 2006)的相关内容 计算种群密度和物种多度及频度。利用SPSS 17.0 对海南苏铁种群平均密度与森林郁闭度及物种多 样性指数进行多元回归分析, F-检验验证其可靠性

(1) 秦坤蓉 (2017) 重庆白马山杜鹃属植物群落学环境特点研究. 硕士学位论文, 西南大学, 重庆. 
$(\alpha=0.05)$ 。借助SPSS 17.0对海南苏铁幼苗及幼树密 度与透光率之间的关系进行曲线估计分析。

\section{结果}

\section{1 海南苏铁所在群落特征}

\subsection{1 群落结构}

本次调查共记录了高度 $\geq 1.5 \mathrm{~m}$ 的维管植物活 个体数 3,196 株共 175 种, 隶属于 53 科 115 属, 其中乔 木层 40 科 63 属, 灌木层 26 科 59 属, 草藤本 32 科 53 属。群落中树高最矮为 $1 \mathrm{~m}$, 最高达 $20 \mathrm{~m}$, 平均树高 $5.48 \mathrm{~m}$; 胸径最小为 $0.4 \mathrm{~cm}$, 最大为 $58 \mathrm{~cm}$, 平均胸 径5.29 cm; 森林郁闭度0.29-0.64, 平均冠幅为 $2.86 \mathrm{~m}^{2}$, 最大冠幅 $80 \mathrm{~m}^{2}$, 群落内物种高度基本在 $15 \mathrm{~m}$ 以下, 占比为 $99.68 \%$, 冠幅面积集中在 $20 \mathrm{~m}^{2}$ 以下, 占比为 $98.85 \%$ 。每 $100 \mathrm{~m}^{2}$ 样方内, 高 $1.5 \mathrm{~m}$ 以 上的立木有 20 种 53 株, 以黄牛木(Cratoxylum

\section{表2 乔木层、灌木层和草本层主要植物物种的多度与频度} Table 2 Abundance and frequency of main species in tree layer, shrub layer, and herb layer
cochinchinense)、银柴(Aporosa dioica)、猪肚木 (Canthium horridum) 等为主。群落垂直结构可分为 乔木层、灌木层、草本层, 群落结构层次清晰, 其 中乔木层可分上下 2 层, 上层高12-20 m, 胸径3$58 \mathrm{~cm}$, 以粉背琼楠(Beilschmiedia glauca)、枝花李 榄(Linociera ramiflora) 等为主; 下层高5-12 m, 胸 径1-40 cm, 以黄牛木、猪肚木等为主。海南苏铁在 灌木层中分布, 但在群落出现频度最高, 种群密度 也是群落内最大, 叶片长度最长可达 $2.45 \mathrm{~m}$, 植株叶 片有多片或是1-2片。草本层主要为草豆冦(Alpinia hainanensis)、海金沙(Lygodium japonicum)等。

\subsection{2 群落多样性}

海南苏铁所在群落多样性分析结果表明, 6个 样方的Simpson多样性指数、Shannon-Wiener多样性 指数和Pielou均匀度指数在不同样方中存在差异 (表 3)。在样方 D中, Simpson多样性指数、ShannonWiener多样性指数和Pielou均匀度指数均达到最大 值, 表明样方 $\mathrm{D}$ 物种丰富且分布较均匀。其他 5 个样 方的几个指数总体相差不大, 样方 C的Simpson多样 性指数、Shannon-Wiener多样性指数最小, 物种丰 富度为样方 $\mathrm{F}$ 最大(10.133), 样方 $\mathrm{C}$ 最小(7.383), 说 明样方 $\mathrm{C}$ 物种种类较少, 物种多样性指数低, 物种 分布相对均匀, 样方 $\mathrm{F}$ 的物种是否出现的不确定性 较高。

\section{2 年龄结构}

种群为群落的基本单位, 其结构能够反映群落 结构的发展趋势。海南苏铁作为一种生长极其缓慢 的植物, 其径向生长不明显, 年龄很难追踪调查。 根据野外调查数据绘制海南苏铁种群龄级结构图 (图1)。整体上, 随着龄级的增加, 海南苏铁种群数

表3 群落物种多样性指数

Table 3 Community species diversity index

\begin{tabular}{|c|c|c|c|c|}
\hline $\begin{array}{l}\text { 样方 } \\
\text { Quadrat }\end{array}$ & $\begin{array}{l}\text { Simpson多样 } \\
\text { 性指数 }\end{array}$ & $\begin{array}{l}\text { Shannon-Wiener } \\
\text { 多样性指数 }\end{array}$ & $\begin{array}{l}\text { Pielou均匀度 } \\
\text { 指数 }\end{array}$ & $\begin{array}{l}\text { 物种丰富 } \\
\text { 度 }\end{array}$ \\
\hline & $\begin{array}{l}\text { Simpson's } \\
\text { diversity index }\end{array}$ & $\begin{array}{l}\text { Shannon diversity } \\
\text { index }\end{array}$ & $\begin{array}{l}\text { Pielou evenness } \\
\text { index }\end{array}$ & $\begin{array}{l}\text { s Species } \\
\text { richness }\end{array}$ \\
\hline A & 0.949 & 3.410 & 0.811 & 9.699 \\
\hline B & 0.951 & 3.360 & 0.831 & 8.252 \\
\hline C & 0.947 & 3.310 & 0.841 & 7.383 \\
\hline D & 0.960 & 3.610 & 0.865 & 9.410 \\
\hline $\mathrm{E}$ & 0.949 & 3.400 & 0.841 & 8.252 \\
\hline F & 0.952 & 3.500 & 0.823 & 10.133 \\
\hline
\end{tabular}




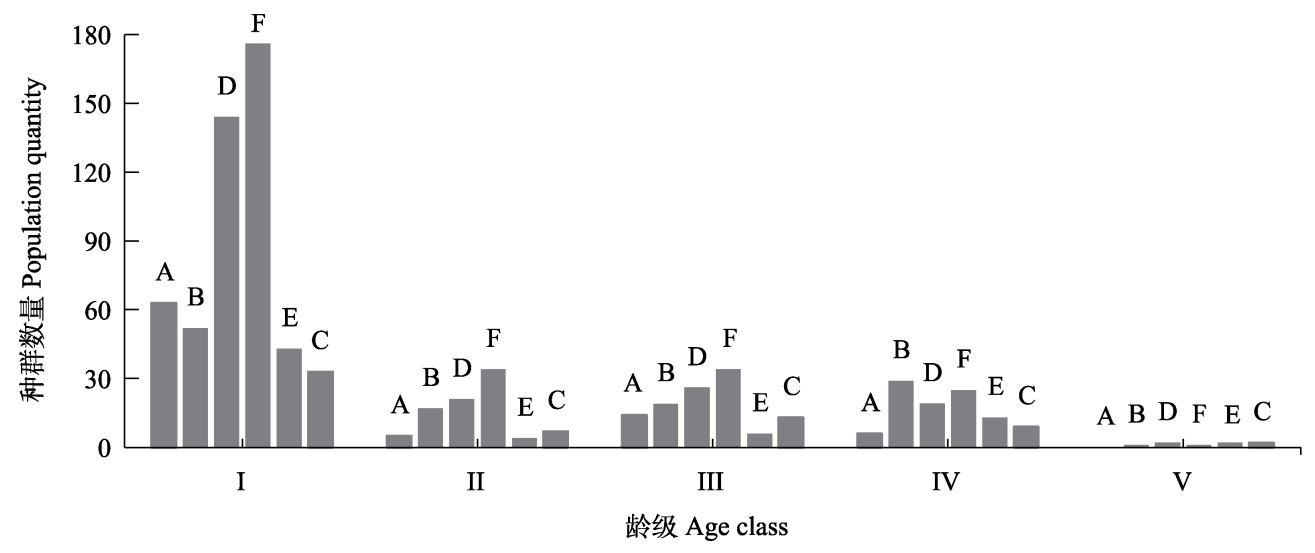

图1 海南省保梅岭省级自然保护区不同样方海南苏铁种群的年龄结构。样方A、B、C、D、E、F详细信息见表1。

Fig. 1 Age structure of Cycas hainanensis population in different quadrat in the Baomeiling Provincial Nature Reserve of Changjiang County, Hainan Province. Details of quadrat A, B, C, D, E, F see Table 1.

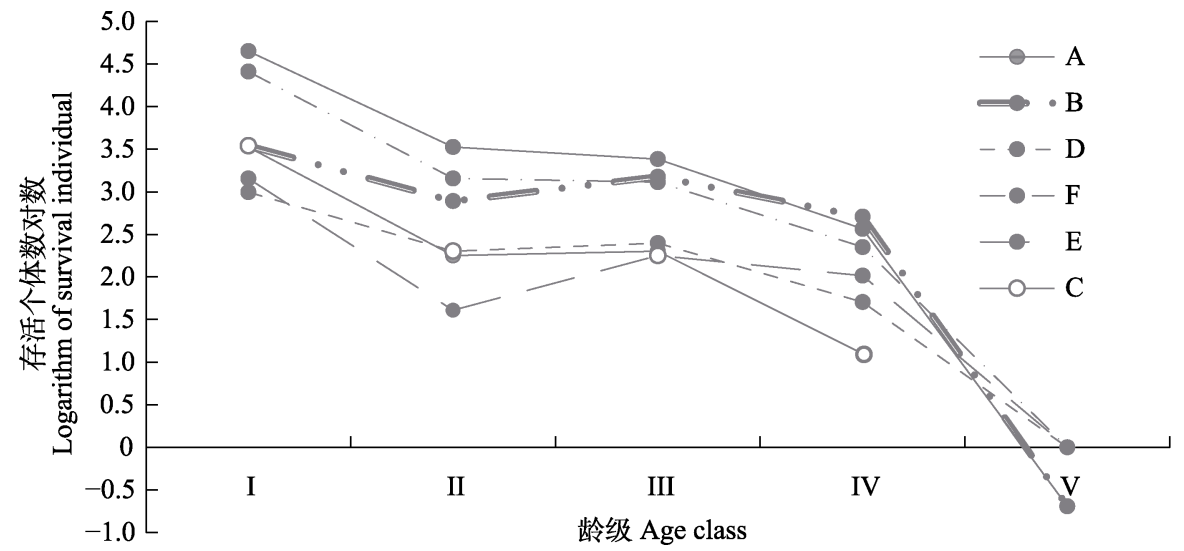

图2 海南省保梅岭省级自然保护区不同样方的海南苏铁种群存活曲线。样方A、B、C、D、E、F详细信息见表1。

Fig. 2 Survival curve of Cycas hainanensis population in different quadrat in the Baomeiling Provincial Nature Reserve of Changjiang County, Hainan Province. Details of quadrat A, B, C, D, E, F see Table 1.

量减少, 种群的幼、青年期(第I、II、III龄级)的株数 与壮、老年期(第IV、V、VI龄级)数量比为711: 109, 幼年个体数量多, 大树个体很少, 老年期个体数量 已没有, 接近于下宽上窄的金字塔型, 有较强的更 新能力, 属增长型种群。在不同的样方郁闭度下, 各个样方中的龄级个体数分布不均, 生长有差异, 样方 $\mathrm{F}$ (郁闭度0.59)中的各龄级个体数量整体上最 多, 样方D (郁闭度0.29)次之。在第龄级中, 样方 $\mathrm{F}$ 的个体数比其他样方都多, 样方 D次之; 第II、III龄 级中, 样方 $\mathrm{F}$ 的个体数最多, 样方 $\mathrm{D}$ 和样方 $\mathrm{B}$ 次之; 在第 $\mathrm{IV}$ 龄级中, 样方 $\mathrm{B}$ 个体数最多, 样方 $\mathrm{F}$ 次之。说 明海南苏铁种群在郁闭度为 $0.29-0.64$ 的森林群落 中生长较好, I龄级幼苗生长最好。

\section{3 存活曲线}

以存活个体数的对数值 (以 10 为底) 作纵坐标,
以龄级为横坐标作图(图2)。存活曲线图显示, 在样 方郁闭度0.29-0.64范围内, 所有样方存活个体数 最大值在I龄级, 表现出丰富的后备资源, 随后递 减，到第III龄级后有一个小幅度增加，之后再减 少到第 $\mathrm{V}$ 龄级存活个体数达到最小(图2)。样方 $\mathrm{A}$ 已 没有 V、VI龄级的个体数, 死亡率随之增加, 使存 活数量逐渐减少, 样方 $\mathrm{C} 、 \mathrm{~F}$ 的存活率呈直线下降, 样方 $\mathrm{C}$ 在第 $\mathrm{V}$ 龄级时存活率为负值, 样方 $\mathrm{F}$ 为 0 ; 而 样方 B、D、E的存活率下降起伏较大, 样方 $\mathrm{E}$ 在第 II龄级时, 存活率达到最小值, 之后缓慢上升, 在 第VI龄级为 0 , 样方 $\mathrm{B}$ 在第II龄级的存活率比样方 $\mathrm{D}$ 稍低, 但 $\mathrm{V}$ 龄级的存活率为负值, 而样方 $\mathrm{D}$ 为 0 。总 体来看, 海南苏铁的存活曲线趋近于Deevey-II型, 但因 $\mathrm{V}$ 龄级的幼树偏少、老树几乎没有，未来会发 生衰退。 
表4 海南省保梅岭省级自然保护区海南苏铁种群空间分布格局。样方A、B、C、D、E、F详细信息见表1。

Table 4 Spatial distribution pattern of Cycas hainanensis population in the Baomeiling Provincial Nature Reserve of Changjiang County, Hainan Province. Details of quadrat A, B, C, D, E, F see Table 1.

\begin{tabular}{|c|c|c|c|c|c|c|c|c|c|c|c|}
\hline $\begin{array}{l}\text { 样方 } \\
\text { Quadrat }\end{array}$ & $\begin{array}{l}\text { 郁闭度 } \\
\text { Forest } \\
\text { canopy } \\
\text { density }\end{array}$ & $\begin{array}{l}\text { 方差 } \\
\text { Variance }\end{array}$ & $\begin{array}{l}\text { 方差均值比 } \\
\text { Average } \\
\text { variance ratio } \\
(D I)\end{array}$ & $t$ & $\begin{array}{l}\text { 负二项参数 } \\
\text { Negative } \\
\text { binomial } \\
\text { parameters }(k)\end{array}$ & $\begin{array}{l}\text { 从生指数 } \\
\text { Cluster } \\
\text { index }(I)\end{array}$ & $\begin{array}{l}\text { 平均拥挤指数 } \\
\text { Average } \\
\text { crowding } \\
\text { index }\left(\mathrm{m}^{*}\right)\end{array}$ & $\begin{array}{l}\text { 聚集指数 } \\
\text { Patchiness } \\
\text { index (Pai) }\end{array}$ & $\begin{array}{l}\text { 扩散型指数 } \\
\text { Type } \\
\text { diffusion } \\
\text { index }\left(I^{\&}\right)\end{array}$ & $\begin{array}{l}\text { 格林指数 } \\
\text { Green } \\
\text { index }(G I)\end{array}$ & $\begin{array}{l}\text { Cassie 指 } \\
\text { 标 Cassie } \\
\text { index }(C A)\end{array}$ \\
\hline$\overline{\mathrm{A}}$ & 0.64 & 31.12 & 3.58 & 5.48 & 4.62 & 2.58 & 11.28 & 1.30 & 1.27 & 2.38 & 0.22 \\
\hline B & 0.51 & 192.1 & 16.14 & 32.2 & 1.75 & 15.14 & 27.04 & 2.27 & 2.15 & 19.9 & 0.57 \\
\hline C & 0.47 & 11.38 & 1.78 & 1.65 & 10.29 & 0.78 & 7.18 & 1.12 & 1.30 & 0.44 & 0.10 \\
\hline D & 0.29 & 134.7 & 26.38 & 11.5 & 5.10 & 15.38 & 26.48 & 1.26 & 1.23 & 12.5 & 0.20 \\
\hline $\mathrm{E}$ & 0.59 & 17.43 & 2.53 & 3.25 & 6.01 & 1.53 & 8.43 & 1.22 & 1.20 & 1.06 & 0.17 \\
\hline F & 0.59 & 311.8 & 11.55 & 22.4 & 3.55 & 10.55 & 37.57 & 1.40 & 1.35 & 31.5 & 0.28 \\
\hline
\end{tabular}

表5 不同透光率下海南苏铁种群不同龄级的密度(株数 $/ 100 \mathrm{~m}^{2}$ )

Table 5 Density (inds./100 $\mathrm{m}^{2}$ ) of Cycas hainanensis population at different age classes under different light transmittance

\begin{tabular}{llllll}
\hline \multirow{2}{*}{$\begin{array}{l}\text { 龄级 } \\
\text { Age class }\end{array}$} & \multicolumn{6}{l}{ 透光率 } & Light transmittance & & \\
\cline { 2 - 6 } & $88.89 \%$ & $66.67 \%$ & $58.33 \%$ & $36.11 \%$ & $21.53 \%$ \\
\hline I & 2 & 7 & 33 & 94 & 8 \\
II & 3 & 2 & 16 & 4 & 0 \\
总计 Total & 5 & 9 & 49 & 98 & 8 \\
\hline
\end{tabular}

\section{4 海南苏铁种群空间分布格局}

海南苏铁的分布格局结果如表4。整体上, $D I>$ 1 , 海南苏铁种群趋于集群分布, 5 个样方差异显著 $(P<0.05)$, 样方 C差异不显著 $(P>0.05)$, 可见海南 苏铁在森林中度郁闭(0.29-0.64)的环境下虽然拥挤 生长, 但聚集程度不同。比较发现, 随着森林郁闭 度的增加, 各聚集程度指标中 $k$ 值有变小的趋势, 说明其种群密度受森林郁闭度的影响。聚集分布可 能是因为种群密度大, 易拥挤在一起, 也可能是所 处的群落环境所致。次生林中, 森林中等郁闭, 光 线较充足, 而小斑块的林窗、林隙环境较多, 导致 其种群聚块分布。还有的样地内裸露的岩石多且大, 导致海南苏铁聚集分布在沿缝边或是大岩石的土 层上。调查中发现样方 $\mathrm{D}$ 的乔木立木较多且高, 林 隙较多, 而岩石的裸露率也大, 导致其种群分布较 为密集。

\section{5 海南苏铁种群数量及密度与样方郁闭度及植} 物多样性的关系

根据 6 个样方 (A-F样方) 的海南苏铁个体数量 和样方面积大小, 得出幼苗(I级)平均密度依次为 5.6、6.7、4.0、16.5、4.7、 20.8 ind. $/ 100 \mathrm{~m}^{2}$, 种群总 密度分别为8.7、11.9、6.4、21.4、6.9、27.0 ind./100 $\mathrm{m}^{2}$ 。从整体可以看出, 各样方内海南苏铁数量分布 不均且有着明显的差异, 其中样方 $\mathrm{F}$ 的平均密度最 大，样方 $\mathrm{D}$ 次之。结合表 1 和表 3 的数据, 对海南苏铁 个体数量进行多元回归分析, 结果发现, 在 6 个分 布有海南苏铁的样方中, 海南苏铁的种群大小、种 群龄级均呈现不相关。因此, 森林郁闭度0.29-0.64 是适宜海南苏铁生长的, 这与全岛调查的结果(海 南苏铁主要生长在森林郁闭度0.4-0.6之间)基本吻 合。目前在野外很少发现其幼苗幼树在更大的森林 郁闭度环境中生长, 可能是因为其不适宜郁闭度大 的森林环境。

\section{6 昌江保梅岭海南苏铁幼苗幼树密度与样方透} 光率的关系

根据模型摘要和参数估算表结果, 3次方模型 的 $R^{2}$ 为 1 , 说明该回归模型的模拟效果很好, 能够 很好地反映数据变化的趋势, 解释率为 $100 \%$ 。3次 方模型为: 幼苗/幼树密度 $=-501.406+3640.561 \times$ 透光率 $-6868.923 \times$ 透光率 $^{2}+3840.098 \times$ 透光率 $^{3}$, 说明海南苏铁幼苗幼树密度随着透光率显著变化 (表5), 在透光率增加时, 其密度增加, 幼苗密度在 透光率36.11\%左右达到最大, 幼树密度在 $58.33 \%$ 达 到最大，而在最大值之后减少，这符合实际情况， 所以海南苏铁的幼苗幼树在透光率 $36.11 \%-58.33 \%$ 范围内能良好生长。从模型的 $F$ 检验结果来看, 3次 项模型的Sig. 值远小于 0.01 , 说明模型成立的统计 学意义非常显著。

\section{3 讨论}

\section{1 海南苏铁所在森林群落特征与其种群的关系} 群落物种的组成分析对了解林下植物主要伴 
生种的生长环境具有重要意义。海南昌江保梅岭自 然保护区海南苏铁所在群落为森林郁闭度中度偏 低的次生林, 主要由175种树木组成, 海南苏铁是 林中主要的伴生树, 在6个样方中共调查到834株, 密度为 $0.139 / \mathrm{m}^{2}$ 。说明目前的森林环境仍较适合海 南苏铁的生长。但由于群落仍属森林群落的恢复阶 段, 均匀度较小, 其与王泽英(2019) ${ }^{\circledR}$ 的研究结果一 致。未来随着森林植被的恢复, 该地区的森林郁闭 度增加, 一些适宜生长在森林郁闭度偏低环境的植 物种群就会受到影响(刘斌等, 2020)。因此, 目前分 布较多的海南苏铁种群随着森林的恢复可能也会 受到影响。

\section{2 海南苏铁种群年龄结构}

根据海南苏铁叶片长度划分大小等级, 用其代 替年龄结构对海南苏铁种群的结构特征进行分析。 昌江保梅岭地区海南苏铁的种群结构与五指山地 区的海南苏铁种群结构相似(谢春平等, 2019)。由于 海南苏铁的生长受到不同森林郁闭度以及种间关 系影响, 其种群在从 $\mathrm{I}$ 龄级幼苗向 $I I$ 龄级幼树及 $\mathrm{V}$ 龄 级大树向 VI龄级老树过渡过程中个体数量明显减 少, 因此分析环境因素对海南苏铁生长的影响是了 解其种群发展、促进存活率提高的关键。黄应锋等 (2013)在对深圳梅林的仙湖苏铁(Cycas fairylakea) 进行研究时指出, 森林群落郁闭度过高是导致仙湖 苏铁种群衰退的一大原因。在次生林发展过程中, 随着森林恢复, 郁闭度增加, 样地内光照逐渐减弱, 各龄级个体对光环境的适应性有所降低。调查发现, 在郁闭度为 0.59 的 $F$ 样方与郁闭度为 0.64 的 $\mathrm{A}$ 样方中, 其种群各龄级个体数呈现下降趋势, 说明森林郁闭 度过高对海南苏铁的生长不利。在其种群发育过程 中, 受到环境与竞争的影响, 幼苗存活率下降, 死 亡率增大, 种群的更新能力下降。因此森林郁闭度 过高可能是海南苏铁种群濒危的原因, 但还需要 进一步研究。

\section{3 海南苏铁种群分布格局}

由研究结果可知, 海南苏铁种群呈聚集分布。 光是影响植物分布的重要生态因子(Rozendaal et al, 2006), 次生林形成, 森林覆盖率和植物多样性随之 增加, 受其立木树种的影响, 小斑块生境也随之形 成, 林窗、裸露的岩石区域都属于群落中的异质性 斑块生境, 生境异质性导致了海南苏铁分布的集群
性, 在群落多样性指数大、森林郁闭度(0.29-0.59) 中等偏低的样方 B、D、F中, 海南苏铁大都聚集于 光线较充足的林窗内或林缘生长。此外, 一定程度 上植物的种群密度也影响着种群分布格局(宋萍等, 2005), 样方内海南苏铁种群密度大主要是由于幼 苗储备多, 导致其聚集性大, 这与宋萍等(2005)的 研究结果一致。海南苏铁为苏铁属植物, 靠种子或 以萌菜的方式繁殖, 种子在受干扰小的阴湿环境中 能大量萌发, 密集而从生, 这也是海南苏铁种群格 局形成的原因之一; 同时, 群落内的立木树种对海 南苏铁的排斥作用及自然灾害是影响其格局形成 的另一原因。调查发现, 不同样方中的海南苏铁个 体数差异大, 在小样方 3 和小样方 41 中海南苏铁的 个体数为 0 , 而在小样方 49 中达 69 株, 说明集群分 布特点明显。

\section{4 海南苏铁种群与森林郁闭度及透光率的关系}

光是影响植物生长的重要因子, 在森林群落中, 森林郁闭度的增加会影响林下的光照强度, 从而影 响林下植物的生长, 特别是对一些需要一定光照环 境的植物, 随着光强变弱, 其种群发育会受到负面 的影响(Hu et al, 2008; Li et al, 2008; 徐飞等, 2010; 张丽, $2019^{(2)}$ )。调查发现, 5 个样方的透光率在 $36.11 \%-58.33 \%$ 时，海南苏铁幼苗幼树密度最大， 说明海南苏铁是一种半喜光的林下植物, 因此可推 测森林郁闭度是影响其种群生长的原因之一。

本文仅从海南苏铁种群结构与空间分布格局 及其所在森林群落特征进行了研究, 今后还可以从 生理生态、种间关系等角度进行。昌江保梅岭被列 为省级自然保护区对海南苏铁的保护有一定的效 果, 但林地中人为干扰与破坏的现象仍然存在, 应 加强保护。

\section{参考文献}

Bell DM, Bradford JB, Lauenroth WK (2014) Early indicators of change: Divergent climate envelopes between tree life stages imply range shifts in the Western United States. Global Ecology and Biogeography, 23, 168-180.

Cao Y, Xue QQ, Qi JY, Liu CY, Wang L, Men LN, Zhang ZW (2019) Effects of light transmittance on the community composition of soil macrofauna in artificial Hippophae

(1) 王泽英 (2019) 上海城市近自然森林群落恢复与种群更新动态 研究. 硕士学位论文, 华东师范大学, 上海.

(2) 张丽 (2019) 海南坡垒种群特征及不同光强对其幼苗生长的影 响研究. 硕士学位论文, 海南大学, 海口. 
rhamnoides plantation. Journal of Shanxi Agricultural Sciences, 47, 2159-2162, 2201. (in Chinese with English abstract) [曹悦, 薛琪琪, 祁靖宇, 柳春雨, 王碚, 门丽娜, 张志伟 (2019) 林内透光率对人工沙棘林大型土壤动物 群落组成的影响. 山西农业科学, 47, 2159-2162, 2201.]

Chen JR (2004) "Panda” in the plant_Cycads. Forest \& Humankind, (12), 4-6. (in Chinese) [陈家瑞 (2004) 植物 界的大熊猫——苏铁. 森林与人类, (12), 4-6.]

Hill KD (2008) The genus Cycas (Cycadaceae) in China. Telopea, 12, 71-118.

Hu QP, Guo ZH, Li CY, Ma LY (2008) Leaf morphology and photosynthetic characteristics of seedlings of a deciduous and an evergreen broad-leaved species under different light regimes in subtropical forests. Acta Ecologica Sinica, 28, 3262-3270.

Huang HM, Dong R, He DN, Xiang YR, Zhang XJ, Chen J, Tao JP (2018) Effects of temporal and spatial variation of canopy structures and light conditions on population characteristics of Fargesia decurvata. Chinese Journal of Applied Ecology, 29, 2129-2138. (in Chinese with English abstract) [黄慧敏, 董蓉, 何丹妮, 向运蓉, 张小晶, 陈娟, 陶建平 (2018) 冠层结构和光环境的时空变化对紫耳箭 竹种群特征的影响. 应用生态学报, 29, 2129-2138.]

Huang YF, Liao SB, Chen Y, Luo SX, Liu DW, Cai G, Sun B (2013) Population characteristics and conservation of Cycas fairylakea. Forest Research, 26, 668-672. (in Chinese with English abstract) [黄应锋, 廖绍波, 陈勇, 罗水兴, 刘东 蔚, 蔡刚, 孙冰 (2013) 深圳梅林仙湖苏铁的种群特征与 保护研究. 林业科学研究, 26, 668-672.]

Li J, Lin JY, He YH, Jiang Y, Liang RL (2016) Population structure and distribution pattern of Cycas bifida in Chongzuo of Guangxi. Guangdong Agricultural Sciences, 43(12), 25-29. (in Chinese with English abstract) [李娟, 林建勇, 何应会, 蒋炏, 梁瑞龙 (2016) 广西崇左叉叶苏 铁种群结构与分布格局研究. 广东农业科学, 43(12), 25-29. ]

Li XW, Chen SL (2008) Effect of shading on photosynthetic characteristics and chlorophyll fluorescence parameters in leaves of Fritillaria cirrhosa. Acta Ecologica Sinica, 28, 3438-3446.

Li YL, Zhang L, Yang XB, Li DH, Zhang K, Wu TT (2017) Study on spatial distribution and population dynamics of wild tea in Hainan Island. Forestry Resource Management, 46(2), 81-87, 138. (in Chinese with English abstract) [李苑 菱, 张丽, 杨小波, 李东海, 张凯, 吴庭天 (2017) 海南 岛野生茶树空间分布及种群动态研究. 林业资源管理, 46(2), 81-87, 138.]

Li YN, Zhang BL, Qin SY, Li SY, Huang XR (2008) Review of research and application of forest canopy closure and its measuring methods. World Forestry Research, 21(1), 40-46. (in Chinese with English abstract) [李永宁, 张宾兰, 秦淑 英, 李帅英, 黄选瑞 (2008) 郁闭度及其测定方法研究与 应用. 世界林业研究, 21(1), 40-46.]
Liu B, Zhang CC, Wang JS, Li ZM, Ouyang YL, Chen W, Chen FS, Bu WS (2020) Characteristic of species diversity in stands of different restoration models in Jiulian Mountain, Jiangxi Province. Forest Research, 33(4), 42-52. (in Chinese with English abstract) [刘斌, 张参参, 汪金松, 李张敏, 欧 阳园丽, 陈维, 陈伏生, 卜文圣 (2020) 江西九连山不同 恢复模式林分的物种多样性特征. 林业科学研究, 33(4), 42-52.]

Luo WH, Tang WX, Huang SX, Liang HL, Zhao B (2014) Ex situ conservation of Cycas debaoensis: A rare and endangered plant. Journal of Zhejiang A \& F University, 31, 812-816. (in Chinese with English abstract) [骆文华, 唐文 秀, 黄仕训, 梁惠凌, 赵博 (2014) 珍稀濒危植物德保苏 铁迁地保护研究. 浙江农林大学学报, 31, 812-816. ]

Mestre L, Toro-Manríquez M, Soler R, Huertas-Herrera A, Martínez-Pastur G, Lencinas MV (2017) The influence of canopy-layer composition on understory plant diversity in southern temperate forests. Forest Ecosystems, 4, 1-13.

Normand S, Zimmermann NE, Schurr FM, Lischke H (2014) Demography as the basis for understanding and predicting range dynamics. Ecography, 37, 1149-1154.

Rozendaal DMA, Hurtado VH, Poorter L (2006) Plasticity in leaf traits of 38 tropical tree species in response to light; relationships with light demand and adult stature. Functional Ecology, 20, 207-216.

Ru WM, Zhang GP, Bi RC, Zhang F, Zhang JT (2007) Population structure and pattern of endangered Ulmus lamellosa in Shanxi. Chinese Journal of Applied and Environmental Biology, 13, 14-17. (in Chinese with English abstract) [茹文明, 张桂萍, 毕润成, 张锋, 张 金屯 (2007) 濒危植物脱皮榆种群结构与分布格局 研究. 应用与环境生物学报, 13, 14-17.]

Song P, Hong W, Wu CZ, Feng L, Fan HL, Zhu H, Lin YM, Zhang Q (2005) Population structure and its dynamics of rare and endangered plant Alsophila spinulosa. Chinese Journal of Applied Ecology, 16, 413-418. (in Chinese with English abstract) [宋萍, 洪伟, 吴承祯, 封䂞, 范海兰, 朱 慧, 林勇明, 张琼 (2005) 珍稀濒危植物杪椤种群结构与 动态研究. 应用生态学报, 16, 413-418.]

Sun XL, Shi SZ, Zhao XY, Xu YY, Hong XJ (2017) Present situation and protection countermeasures of wild and endangered plants in minimal population in Hainan Province. Journal of Green Science and Technology, (18), 11-13, 38. (in Chinese with English abstract) [孙湘来, 石 绍章, 赵小迎, 许洋瑜, 洪小江 (2017) 海南省极小种群 野生濒危植物现状与保护对策. 绿色科技, (18), 11-13, 38.]

Tang YJ, Liao JP (2001) Studies on comparative anatomy of the pinnae of six species of Cycas. Chinese Bulletin of Botany, 18, 615-622, 604. (in Chinese with English abstract) [唐源江, 廖景平 (2001) 六种苏铁属植物的羽 片比较解剖学研究. 植物学通报, 18, 615-622, 604.]

Xie CP, Wu CK, Fu G, Lai SF, Fang Y, Wang HC (2019) 
Population structure characteristics and dynamics of Cycas hainanensis in Wuzhi Mountains, Hainan Province. Journal of Central South University of Forestry \& Technology, 39(1), 77-85. (in Chinese with English abstract) [谢春平, 吴昌鬼, 付桂, 赖水发, 方彦, 王华晨 (2019) 五指山地 区海南苏铁种群结构特征与动态. 中南林业科技大学学 报, 39(1), 77-85.]

Xie ZQ, Chen WL, Liu ZY, Jiang MX, Huang HD (1999) Spatial distribution pattern of Cathaya argyrophylla population. Acta Botanica Sinica, 48, 3-5. (in Chinese with English abstract) [谢宗强, 陈伟烈, 刘正宇, 江明喜, 黄汉 东 (1999) 银杉种群的空间分布格局. 植物学报, 48, 3-5.]

Xue JH (2006) Forest Ecology. China Forestry Publishing House, Beijing. (in Chinese) [ 薛建辉 (2006) 森林生态学. 中国林业出版社, 北京.]

Xu F, Guo WH, Xu WH, Wang RQ (2010) Effects of light intensity on growth and photosynthesis of seedlings of Quercus acutissima and Robinia pseudoacacia. Acta Ecologica Sinica, 30, 3098-3107. (in Chinese with English abstract) [徐飞, 郭卫华, 徐伟红, 王仁卿 (2010) 不同光环境对麻栎和刺槐幼苗生长和光合特 征的影响. 生态学报, 30, 3098-3107.]

Yang XB (2015) The Colored Illustrated Flora of Hainan Province (Vol. 2). Science Press, Beijing. (in Chinese) [杨 小波 (2015) 海南植物图志(第2卷). 科学出版社, 北 京.]
Zhang J, Shang guan TL, Duan YH, Guo W, Liu WH, Guo DG (2014) Age structure and dynamics of Quercus wutaishanica population in Lingkong Mountain of Shanxi Province, China. Chinese Journal of Applied Ecology, 25, 3125-3130. (in Chinese with English abstract) [张婕, 上官 铁梁, 段毅豪, 郭微, 刘卫华, 郭东罡 (2014) 灵空山辽 东栎种群年龄结构与动态. 应用生态学报, 25 , 3125-3130.]

Zhao RB, Yang XB, Li DH, Qi CL, Li JB (2018) Study on geographical distribution and distribution characteristics of cyatheaceae in Hainan Island. Forestry Resource Management, 47(2), 65-73, 97. (in Chinese with English abstract) [赵瑞白, 杨小波, 李东海, 戚春林, 李剑碧 (2018) 海南岛杪椤科植物地理分布和分布特征研究. 林业资源管理, 47(2), 65-73, 97.]

Zheng YR (1997) The applicability of various methods in analysis of Picea mongolica population spatial distribution pattern. Acta Phytoecologica Sinica, 21, 480-484. (in Chinese with English abstract) [郑元润 (1997) 不同方法 在沙地云杉种群分布格局分析中的适用性研究. 植物生 态学报, 21, 480-484. ]

Zhou JL, Zheng SZ, Yang C (1992) Plant Ecology. Higher Education Publishing House, Beijing. (in Chinese) [周纪伦, 郑师章, 杨持 (1992) 植物种群生态学. 高等教育出版 社, 北京.]

(责任编委：张健 责任编辑: 黄祥忠) 